\title{
Causes of road accidents in Botswana: An econometric model
}

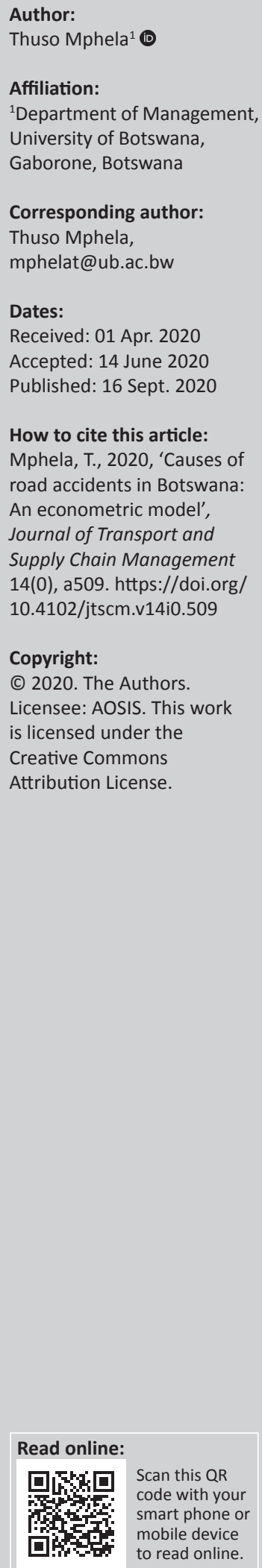

Background: Road traffic accidents claim over 1.3 million lives annually around the globe and remain a key socio-economic challenge today. At 20.1 per 100 000, Botswana's fatality rate is higher than the global average of 17.4. Previous studies on the causes of road crashes in Botswana have not explored statistical causality. This study is thus grounded on the theory of causality.

Objectives: This study sought to determine the causes of road traffic accidents and fatalities in Botswana. For this purpose, the article discusses the accident count model based on Botswana data.

Method: The study used road accident data from 2008 to 2017. Econometric modelling on Gretl was used to compute two ordinary least squares (OLS) regression models. Manual elimination of insignificant variables was performed through the iterations.

Results: Both models are statistically significant at $p \leq 0.001$, but the accident count model, with an adjusted $R^{2}$ value of 0.99 against 0.83 , is more robust and has a better predictive power as opposed to the fatalities model. At the individual variable level, the analysis shows mixed results.

Conclusion: The study contends that increased exposure and night-time travel increase road crashes, whilst expansion of road infrastructure is inversely related to road accidents. An increase in both population density and exposure leads to increased fatalities. Regulating the importation of used vehicles and investment in rail transport is a potential policy panacea for developing economies. Future studies should investigate the causes of pedestrian fatalities and night accidents.

Keywords: road traffic accidents; accident modelling; econometric modelling; forecasting; exposure; night-time travel; road infrastructure.

\section{Introduction}

Road traffic accidents are becoming a serious socio-economic challenge of the 21st century, causing loss of life and property. Unfortunately, with a share in excess of $90 \%$ of the global accident count, developing economies are the hardest hit compared to their developed counterparts (World Bank 2017), whilst facing the innumerable challenges of poverty and poor healthcare. Botswana is no exception. Globally, the annual road traffic carnage is estimated to have grown from 1.2 million to 1.3 million (World Health Organization [WHO] 2015). The World Bank (2017) reports that approximately 20-50 million people are seriously injured annually. In Botswana, the period under review has recorded minimum and maximum annual road fatalities of 377 and 497, respectively. The rate of 23.6 road fatalities per 100000 recorded in 2015 showed little progress since 2011, when a rate of 23.9 was recorded, and the WHO Decade of Action for Road Safety 2011-2020 was adopted with a view to cut fatalities in half by 2020 (Government of Botswana 2018b; World Bank 2017). In the member nations of the Organisation for Economic Co-operation and Development (OECD), the average road accident fatality rate is 8 per 100000 people (World Bank 2017). In 2017, 142 out of 444 fatalities in Botswana were pedestrians. Generally, the fatality rates in Botswana have been steady since 2005, characterised by small spikes around an average of 430 (see Table 1). A significant piece of legislation in the Road Traffic Act (Government of Botswana 2008), whose major change was the increase of road traffic fines (some saw increases of over 200\%), was amended in 2008 with a view to curbing road accidents, among other reasons. Unfortunately, there has been no evidence that this brought any significant changes (Mphela 2011).

In its annual report, Statistics Botswana opines that the surge in the motor vehicle population has increased the chances of road accidents and fatalities (Government of Botswana 2018a). Moyer, 
Eshbaugh and Rettig (2017) posit that the population of motorised vehicles will continue to grow globally for the next few decades into 2050, with the exception of OECD countries. A previous study on road traffic accident causes in Botswana by Mupimpila (2008) concluded that the causes of accidents included speeding, drunken driving and congestion, whilst a study Pego (2009) attributed the majority of accidents to human/driver behaviour and, to a lesser degree, vehicle factors and the roadway environment. Pego's study was done at city level rather than national. However, neither research employs statistical causal methods of analysis. Moyer et al. (2017) lament the lack of research on the causes and impact of road traffic accidents in many developing countries. This is an anomaly considering the high level of accidents and fatalities that occur in these countries.

This study sought to investigate the causes of accidents in Botswana using accident incidence statistical records from 2008 to 2017. At the time of analysis, reliable data were only available until 2017. Production of the annual traffic statistics by Statistics Botswana tend to take time, as collection of data is done by the traffic police before the cleaning and validation process, resulting in a delay of at least 1 year. Two accident severity models - accident count and fatalities - are computed using ordinary least squares (OLS) regression modelling. Modelling the causes of accidents allows us to determine the major contributors and identify opportunities for interventions (Benner 1979; Hakkert \& Braimaister 2002). In line with the theory of causality, the study hypothesises that road traffic accidents and fatalities can be modelled and predicted with high levels of certainty. Specifically, it posits that accidents and fatalities can be explained by vehicle characteristics, the amount of travel and the time of travel. Further, the interaction between the dependent and explanatory variables will differ between the two models.

\section{Literature review}

The causes of road traffic accidents are complex phenomena that researchers have to confront (Rolison et al. 2018). This is because there is a plethora of factors interacting simultaneously. However, the bulk of accident occurrences are blamed on driver behaviour (Luke \& Heyns 2014; Mphela 2011). The World Health Organization (2004) opines that the use of the word 'accident' has somehow been understood to be synonymous with inevitability and unpredictability, rendering systems helpless in managing the eventual outcomes of crashes. It indicates that accidents are bound to occur, and there is nothing we can do about it. It is also critical to note that methodological choices and the jurisdiction of accidents tend to lead to different conclusions on the causes of road traffic accidents. Perrels et al. (2015) argue that weather is a critical component in dealing with road accidents. A study by Parvareh et al. (2018) found that air temperatures had an influence on pedestrian and motorcycle accidents in Iran. In Catalonia (Spain), Basagana et al. (2015) found that the risk of road crashes associated with driver performance factors increased by almost 3\% during heat waves.

\section{Exposure}

Vehicular mileage or amount of travel is commonly used to quantify exposure (Lloyd \& Forster 2014; Naqvi, Quddus \& Enoch 2020; Shen et al. 2020). WHO (2004) argues that the risk for one journey may be small but that the amount of risk accumulates with each trip. There is evidence that the risk of death from traffic injuries increases with the amount of exposure (Pulido et al. 2016). Naqvi et al. (2020) investigated the effect of fuel prices in Britain. Their study found that the number of fatal crashes decreased by $0.4 \%$ for every $1 \%$ increase in fuel prices. They concluded that fuel prices mediate fatal crashes by reducing exposure as a result of less travel and moderated driver behaviour like speed reduction. Lloyd and Forster (2014) argued that the use of vehicular mileage does not allow for disaggregation, and therefore to overcome this, they simulated both vehicle type and road types to estimate traffic flows. In order to deal with the limitation of disaggregation of travel distance, Shen et al. (2020) used the length of driving time to measure exposure, arguing that it is a more reliable measure of exposure.

\section{Population}

The concept of exposure discussed above implies that the rate of accidents is likely to increase with the amount of travel. WHO and countries use a common globally accepted epidemiological standard where accident counts and fatalities are expressed as a function of population, for example, fatalities per 10000 or 100000 people. This standard helps us to compare the severity of the challenge between countries and regions. In comparing accident prevalence in districts across China, Ding et al. (2017) found that places with higher population densities recorded higher accidents per unit of population. Road accident literature normally disaggregates demographic data to determine the level of risk experienced by different groups of society. However, in this study aggregate population is used.

\section{Vehicle characteristics}

At a disaggregated level, the number of cars on the road has a significant impact on road traffic accidents. Ashraf et al. (2019) concluded that the rate of increase in the vehicle population in South Korea exceeded the supply of roads, leading to increased road accidents. Vehicle characteristic definitions tend to vary from country to country depending on the method of recording accidents. Torrao, Coelho and Rouphail (2012) used the make, model, wheelbase, size, weight, engine size, age of car and type of fuel the vehicle used in their road accident study in Portugal. The study found that weight differentials in accidents involving more than one vehicle played a significant role in the severity of the accident. Heavier vehicles tended to protect the occupants better than lighter ones, whose occupants were likely to suffer more severe injuries or fatalities when heavier vehicles were involved. Whereas newer vehicles tended to be safer in single-vehicle crashes, this advantage was lost when more than one vehicle was involved. Cioca and Ivascu (2017) 
found that the top four vehicle types that are highly likely to be involved in road accidents in Romania are cars (65\%), intervention vehicles (55\%), auto trailers (50\%) and lorries/ trucks (35\%). In South Korea, passenger cars (68\%) and trucks $(13 \%)$ account for higher shares of road crashes (Ashraf et al. 2019).

\section{Road infrastructure}

Road quality and supply not only are critical for facilitating efficient movement but are also instrumental in the management of road safety. In Romania, $60 \%$ of road traffic accidents were caused by road alignment (Cioca \& Ivascu 2017). This was further corroborated by Cristian and Lucian (2019), who concluded that road design has a significant bearing on road safety. Their study, also done in Romania, revealed that the construction of sidewalks, expanding the number of lanes in certain sections of the road and elevating pedestrian crossings reduced the occurrence of road traffic accidents. Levulytè et al. (2017) analysed pedestrian accidents in Europe too, and they identified pedestrian crossing design as a contributor to road traffic accidents. A study by Rahimi et al. (2020) found a significant influence of road engineering on single-vehicle truck crashes in Iran. Even though differences were observed between accident rates on different road types, the regression model computed by Ashraf et al. (2019) revealed that road type has little impact on road accidents. On the contrary, Štefko, Kubák and Bačík (2014) found expressways to have a significant impact on the reduction of road accidents that caused death and injury in the Slovak Republic. In South Korea, Ashraf et al. (2019) concluded that a lower rate of road surface expansion against a higher rate of vehicle population increase was a major explanator of increased road accidents.

\section{Time of travel}

The time of travel is normally expressed in two categories, daytime or night-time. Ashraf et al. (2019) posit that whereas road accidents occur almost equally during the night and day, more fatalities are recorded during night-time travel. John and Shaiba (2019) concluded that accident rates peak late at night, whilst during the day most accidents happen at traffic peak hours with little space between vehicles in Dubai. A study in China by Wang et al. (2019) found that accidents that occur late in the night tended to be more fatal than those occurring during the day. Closer to home, in Botswana, South Africa and Namibia, there is evidence that fatal accidents tend to happen in the night-time. This could be explained by challenges of visibility (twilight/dawn conditions are more challenging), but there is also a chance that this occurs when human policing is low (Mphela 2011), a time when reckless driving tends to be prevalent. The latter argument is further supported by Ashraf et al. (2019), who opined that night-time accident occurrence in South Korea was explained by other road use factors besides visibility challenges.

In conclusion, increased exposure leads to an increase in the risk of accidents occurring, whilst densely populated areas are likely to experience more traffic accidents than less densely populated ones. Different vehicle characteristics affect road accidents in different ways. Firstly, passenger cars are leading contributors to accident statistics, whilst heavier vehicles are likely to increase the severity of accidents if they are involved. On the other hand, increased road supply may lead to a decrease in road accidents. When it comes to the time of travel, more fatal accidents are likely to occur at night.

\section{Research methods and design}

This longitudinal study employs the determinant variable theory of road traffic accident investigation (Benner 1979). The objective is to determine a causal relationship between the different factors, whether population, environmental, economic, vehicular characteristic or pure chance and accident counts. Sets of data used in such models are not always ideal but are normally influenced by availability and quality. For example, Shen et al. (2020) used data on the length of travel time instead of the travel distance, because the former was available in disaggregated form. For this purpose, the study uses the TRafikk, ULykker og Skadegrad (traffic, accidents and injury degree [TRULS]) model, developed under the Demand Routière, les Accidents et leur Gravité (DRAG) family of models (Fridstrøm 1999). The TRULS model takes a multilayered approach, resulting in multiple equations that measure direct effect instead of a mix of both direct and indirect effects at the same time. For purposes of this article, the researcher focused specifically on the accident and severity models that measure the causes of accidents and fatalities, whilst testing the ability of the models to predict their occurrence.

\section{Discussion of variables and data}

Road traffic accident statistics are riddled with challenges regarding the precision and availability of data (Štefko et al. 2014), owing to a lack of resources that results in underreporting (Rolison et al. 2018) and to weaknesses in datacapturing instruments. Pulido et al. (2016) posit that there is a dire need for data on factors that measure direct exposure in many countries. Sometimes, authorities charged with recording data use different criteria for the recording of accident data. A study in Botswana by Pego (2009) found that traffic police used two different forms to record accident data, leading to inconsistencies. It is for this reason that Rolison et al. (2018) recommended a continuous review of police accident data forms. For example, a discussion with traffic police revealed that in Botswana, statistics on fatalities normally register lives lost on the accident spot. There are efforts to follow accident cases beyond this approach, so that if an eventual death is determined to be caused by the accident, then it can be recorded in the road fatality statistics. Minor crashes are likely not to be reported (Fridstrøm 1999), thereby distorting the data on accident occurrence, which technically translates to the probability of severity. It would seem that challenges with road traffic accident data are not new. Benner (1979) attributes this to the varying interests (difficult to reconcile) of different 
stakeholders, like the police, insurers and litigators, among others, for the same incident.

This study uses panel data retrieved from various sources. The majority came from Statistics Botswana annual reports, augmented by data from the Southern African Customs Union and the World Bank. The accident data was further corroborated with the Motor Vehicle Accident Fund Botswana statistics for purposes of consistency. Detailed data on accident characteristics could only be sourced from the annual Botswana Transport and Infrastructure Statistics Reports from 2008 to 2017. Much of this data is supplied by the Botswana Police Service traffic division to Statistics Botswana. The data summary given in Table 1 is computed from the annual Botswana Transport and Infrastructure Statistics Reports (Government of Botswana 2018b), except for variables on fuel imports.

Exposure is considered the most important variable in explaining severity (Fridstrøm 1999). Normally, this variable is measured by the vehicle mileage or amount of travel by foot for pedestrians (Hakkert \& Braimaister 2002), which translate to the amount of activity on the roads. The last time Botswana attempted to measure this through traffic counts was in 2008. Consequently, the researcher used country level data on fuel imports as a proxy variable. This is not in any way a perfect measure, but it is a plausible alternative given that fuel consumption is directly proportional to vehicle kilometres, holding everything else constant. Three variables were created, one where the absolute Botswana pula (BWP) import value was used, one where this value was controlled for exchange rates and one representing the volume of imports. The latter variable was created by adjusting fuel imports for currency and price fluctuations to prevent hoarding effects. Botswana is a net importer of fuel; therefore, the United States dollar/Botswana pula (USD/BWP) exchange rate and the price per barrel in USD were used. To give context, the BWP averaged P8.37, with a minimum of P6.16 and a maximum of P11.30, to the USD over the 10 years. On the other hand, crude oil prices were as

TABLE 1: Botswana road traffic accident summary statistics (2008-2017).

\begin{tabular}{lccccc}
\hline Variable & Mean & Median & SD & Min. & Max. \\
\hline Accident count & 18244 & 17894 & 1222.5 & 16641 & 20415 \\
Fatalities & 430.7 & 427.5 & 35.51 & 377 & 483 \\
Fuel imports (million BWP) & 6155.40 & 6131.57 & 1744.24 & 3309.47 & 8718.05 \\
Fuel imports (million USD) & 763.08 & 773.82 & 214.82 & 439.17 & 1038.90 \\
$\begin{array}{l}\text { Fuel imports (volume, } \\
\text { thousands of litres) }\end{array}$ & 10010 & 10640 & 2184 & 4406 & 11820 \\
Road infrastructure (km) & 24450.03 & 24158.82 & 6782.29 & 18012 & 31746.70 \\
Population (thousands) & 2035.3 & 2086.5 & 191.93 & 1755 & 2264 \\
Cars & 226200.9 & 232632.5 & 69112.44 & 120783 & 328572 \\
LDVs & 102445.8 & 103009 & 7487.37 & 88547 & 111129 \\
Trucks & 25193.2 & 23924 & 8554.49 & 15321 & 46729 \\
Buses & 13965.7 & 14456 & 4247.40 & 4541 & 19624 \\
Tankers/horses & 2768.6 & 2851.5 & 431.66 & 1892 & 3208 \\
Daylight accidents & 10936.6 & 10718.5 & 881.37 & 9895 & 12558 \\
Night accidents & 7307.1 & 7248.5 & 372.16 & 6719 & 7931 \\
\hline
\end{tabular}

BWP, Botswana pula; USD, United States dollar; LDVs, light duty vehicles; SD, standard deviation. volatile, averaging $\$ 76.06$, with minimum and maximum prices of $\$ 43.58$ and $\$ 99.67$, respectively. A lot of this behaviour followed the global economic meltdown of 2008. Data on fuel imports was retrieved from the International Merchandise Trade statistics reports from Statistics Botswana (Government of Botswana 2014, 2015, 2016, 2018a, 2019a, $2019 \mathrm{~b}$ ) and augmented with sources from the Southern African Customs Union (SACU Secretariat 2013). Statistics Botswana personnel were also consulted to fill gaps in the statistical data.

The accident count data were categorised into daylight accidents or night accidents, representing the actual occurrence of road accidents during the day or night, respectively. Botswana generally has longer days than nights, except in winter, when the shortest day lasts for just above 10 hours and 36 minutes. For purposes of this paper, daylight was from 06:00 to 18:00. Botswana, to a large extent, has a unique context in this regard because of its larger presence of roaming animals, especially along unfenced roads - increasing the chances of accidents at night. In Fridstrøm's model, this was a dummy variable, whereas in this case, it is the actual count of accidents occurring during the two parts of the day.

Data on the road network (measured in kilometres) prior to 2011 is rather unreliable because the Transport and Infrastructure Statistics report records only the road infrastructure under central government maintenance, leaving out roads under the care of local governments. Taking the cue that the network remained constant over more than 5 years before 2011, a decision was made to equate 2009 to 2010, and only 2008 was varied because records showed an increase in $30 \mathrm{~km}$ from 2008 to 2009. This is likely to pose challenges regarding the variable significance.

Vehicle type in Botswana is categorised into five kinds: cars (passenger cars), light duty vehicles (LDVs), trucks, buses and tankers/horses. In the conceptual framework, these are referred to as 'vehicle characteristics'. Tankers and horses are grouped for statistical reporting with no reasons given, despite the two being different configurations.

\section{Data analysis}

The study built two different aggregated models to determine the explanatory factor of a number of different variables on accident occurrence and fatalities at a macro level. Using 10-year secondary data, an econometric model was built to determine the causes of accidents and fatalities. After the data were cleaned, Statistical Package for Social Sciences (SPSS) version 26 was used to run regression curve estimates of all independent variables against fatalities and accidents as dependent variables. Only the fuel imports variable returned a significant relationship with fatalities. When the same exercise was carried out on accidents as a dependent variable, only road infrastructure did not register a significant relationship. This initial evaluation of variables is critical in visualising the singular effects of explanatory variables independent of 
others. Both OLS regression models were run on Gretl software (Cottrell \& Lucchetti 2018), first treating all variables as explanatory variables. After every run, the least significant variable (using $p$-values) was manually removed and the model rerun until all the variables in the model were significant. A counter process, where eliminated variables were added back into the model, was also performed to validate the model. Further, a number of treatments/transformations were also done on the data, and different models were run to explore non-linear relationships. For example, among the transformations done were logs and percentage changes. However, these did not improve the quality of the regression models. Contrary to Conto and Ferreira's (2011) assertion, simple OLS models provided a better fit than log-linear models using this data. Fridstrøm (1999), whose work this study is largely based on, also used logs. Therefore, the two econometric models computed in this article follow the formula given in Equation (1):

$y_{t}=\beta 1+\beta 2 x_{t}+e t \quad t=1,2, \ldots, T$

The formula allows us to measure the temporal effects of the different factors. Therefore, we are able to determine the implications of the explanators on the dependent variables over time.

\section{Ethical consideration}

This study was primarily based on publicly available secondary data with no human subjects involved. Further, the study did not pose any harm to any person's character, business or organisation. However, the researcher takes personal responsibility for the outcome of the results.

\section{Results and discussion}

Two accident severity regression models are presented and discussed next. These were the best model results after numerous runs.

\section{Accident count model}

The accident count model is presented in Table $2 \mathrm{a}$ and $\mathrm{b}$. Seven variables returned significant outcomes when regressed against road accident counts. The model also has a higher explanatory power, with an $R^{2}$ value of 0.999 . Therefore, it explains $99 \%$ of the variation in the accident count. Further, an adjusted $R^{2}$ value of 0.998 demonstrated the strength of the model. Even with relatively few observations for a regression model, a test for normality of errors failed to reject the null hypothesis. Therefore, the errors were normally distributed, proving there is a statistically significant relationship between the dependent variable and its explanators. An alternative model to the model presented next was computed, substituting fuel imports (BWP) with fuel imports (USD). The result was a good model with the same $R^{2}$ value but a weaker adjusted $R^{2}$ value.
TABLE 2a: Accident count ordinary least squares model.

\begin{tabular}{lcccc}
\hline Variable & Coefficient & SE & $\boldsymbol{t}$-ratio & $\boldsymbol{p}$ \\
\hline Constant & 14099.6 & 1290.20 & 10.93 & $0.0083^{* *}$ \\
Fuel imports (BWP) & $-2.87261 \mathrm{e}-07$ & $3.15369 \mathrm{e}-08$ & -9.109 & $0.0118^{*}$ \\
Trucks & -0.0620868 & 0.00474262 & -13.09 & $0.0058^{* *}$ \\
Tankers/horses & -1.13762 & 0.0841655 & -13.52 & $0.0054^{* *}$ \\
Cars & 0.00899768 & 0.000928700 & 9.688 & $0.0105^{*}$ \\
Night accidents & 1.21536 & 0.143785 & 8.453 & $0.0137^{*}$ \\
Road infrastructure & -0.0579558 & 0.00751920 & -7.708 & $0.0164^{*}$ \\
Fuel imports (volume) & 0.000112590 & $9.58153 \mathrm{e}-06$ & 11.75 & $0.0072^{* *}$ \\
\hline
\end{tabular}

*, Statistical significance $=p \leq 0.01$;*, Statistical significance $=p \leq 0.001$.

BWP, Botswana pula; SE, standard error.

TABLE 2b: Summary statistics for accident count model.

\begin{tabular}{lc}
\hline Statistic & Value \\
\hline Mean dependent var & 18243.70 \\
SD dependent var & 1222.471 \\
Sum squared resid & 4698.409 \\
SE of regression & 48.46859 \\
$R^{2}$ & 0.999651 \\
Adjusted $R^{2}$ & 0.998428 \\
$F(7,2)$ & 817.6147 \\
$p$-value (F) & 0.001222 \\
Log-likelihood & -44.95136 \\
Akaike criterion & 105.9027 \\
Schwarz criterion & 108.3234 \\
Hannan-Quinn & 103.2472 \\
Rho & -0.715964 \\
Durbin-Watson & 3.395981 \\
\hline
\end{tabular}

Note: Test for normality of residual: Null hypothesis = error is normally distributed. Test statistic: Chi-square $(2)=1.26522$, with $p$-value $=0.531203$.

SD, standard deviation; SE, standard error; var, variable; resid, residual.

The variables tankers/horses $(p \leq 0.001)$ and night accidents ( $p \leq 0.01$ ) had a particularly significant influence on the accident counts, whereas fuel imports $(B W P)(p \leq 0.01)$ and fuel imports (volume) $(p \leq 0.001)$ had coefficients that were weak but statistically different from 0 . The latter's effect on accident count is consistent with the literature. There are three variables whose coefficients had unexpected signs. Fuel imports (BWP), trucks and tankers/horses all had negative coefficients. In terms of road accident literature, all these variables are known to grow in the same direction as accident counts. In other words, they have been known to exhibit a positive relationship with accident counts. Growth and improvement in road infrastructure have a decreasing effect on road accident counts. It is worth noting the significant impact of the night accidents variable on the accident count.

\section{Fatalities model}

In the fatalities model in Table $3 a$ and $b$, the regression model returned three fewer significant independent variables. As opposed to the accidents model, it excluded the variable night accidents, tankers/horses and trucks. The output indicated fuel imports (USD), population and cars as significant explanatory variables at a significance level of $p \leq 0.001$, whereas fuel imports (volume) was significant at $p \leq 0.01$. An $R^{2}$ value of 0.91 is testament of a very strong model, explaining $91 \%$ of the variation in the fatalities. However, population had a stronger coefficient than all the independent variables. Whereas the other three variables were significant in the 
TABLE 3a: Fatalities ordinary least squares model.

\begin{tabular}{lcccc}
\hline Variable & Coefficient & SE & $\boldsymbol{t}$-ratio & $\boldsymbol{p}$ \\
\hline Constant & -525.314 & 194.601 & -2.699 & $0.0428^{*}$ \\
Cars & -0.00236305 & 0.000409773 & -5.767 & $0.0022^{* *}$ \\
Population & 0.782475 & 0.144478 & 5.416 & $0.0029 * *$ \\
Fuel imports (volume) & $8.10179 \mathrm{e}-06$ & $2.87515 \mathrm{e}-06$ & 2.818 & $0.0372^{*}$ \\
Fuel imports (USD) & -0.239997 & 0.0362785 & -6.615 & $0.0012^{* *}$ \\
\hline
\end{tabular}

*, Statistical significance $p \leq 0.01 ; * *$, Statistical significance $p \leq 0.001$.

$\mathrm{SE}$, standard error; USD, United States dollar.

TABLE 3b: Summary statistics for fatalities model.

\begin{tabular}{lc}
\hline Statistic & Value \\
\hline Mean dependent var & 430.7000 \\
SD dependent var & 35.50602 \\
Sum squared resid & 1043.016 \\
SE of regression & 14.44311 \\
$R^{2}$ & 0.908073 \\
Adjusted $R^{2}$ & 0.834531 \\
$F(4,5)$ & 12.34770 \\
$p$-value (F) & 0.008379 \\
Log-likelihood & -37.42582 \\
Akaike criterion & 84.85164 \\
Schwarz criterion & 86.36457 \\
Hannan-Quinn & 83.19197 \\
Rho & -0.508915 \\
Durbin-Watson & 2.934763 \\
\hline
\end{tabular}

Note: Test for normality of residual: Null hypothesis = error is normally distributed. Test statistic: chi-square $(2)=1.81406$ with $p=0.403722$.

$\mathrm{SD}$, standard deviation; $\mathrm{SE}$, standard error; var, variable; resid, residual.

model, they had minimal explanatory power on fatality counts. Added to this, the coefficient signs of cars and fuel imports (volumes) were expected to be positive instead of negative.

The model was also tested for the normality of errors using the chi-square test. The result was an insignificant $p$-value, which means that the hypothesis that errors were normally distributed could not be rejected. Consequently, the model proves that fatality rates are associated with the amount of activity on the national roads.

The accident count model $\left(R^{2}=0.99\right)$ is more robust statistically - it has a better explanatory and forecasting power than the fatalities model $\left(R^{2}=0.90\right)$. The latter has an adjusted $R^{2}$ value of 0.83 , whereas that of the former is 0.99 . This is despite the fatalities model having three fewer explanatory variables. Both the variables $L D V s$ and buses were insignificant in both models. Findings on the buses variable are particularly inconsistent with those of Romilly (1999), whose study found increased use of buses to have a negative effect on road crashes.

The two models, however significant, present rather surprising outputs considering the expected effects of the different individual variables on dependent variables. To start with, the accident count variable is insignificant in explaining road fatalities. Logically, one expects that the number of accidents would have a bearing on fatality counts. However, Wang et al. (2019) observed a contrasting rise of accidents against declining fatalities. This could be explained by other variables like improved safety of cars, which were not accounted for in this model. Regarding accident count, Fridstrøm (1999) opines that it can be just an act of randomness, with neither particular pattern nor explanation. For example, you can record 10 accidents that lead to no single fatality but have a single accident occurrence that results in 10 fatalities, demonstrating the level of uncertainty with which fatalities can be observed.

In the fatalities model, population was the strongest determinant of fatalities, followed by fuel imports (USD), even though the latter recorded an inverse relationship. This supports the argument that the chances of road fatalities increase with population growth. On the other hand, the fuel imports (volume) variable recorded a logically positive coefficient, even though the effect was quite negligible. In both models, the fuel spend variables (fuel imports [USD] and fuel imports $[B W P])$ exhibited inverse relationships. The unexpected effect of these two variables might have suffered from hoarding effects of oil prices and exchange rates. Therefore, we can conclude that fuel imports (volume) is a better proxy variable for exposure.

The cars variable is the only explanator that reported different coefficient signs in each model. In the accident count model, the coefficient was positive; however, in both models the strength of the coefficients was almost the same. However, the coefficient in the accident count model is consistent with the literature, as an increase of cars on the roads increases the chances of accident occurrence. In the accident count model, the trucks variable exhibited an inverse relationship. This is contrary to the findings of Cioca and Ivascu (2017) and Ashraf et al. (2019), who found that trucks are among the leading vehicle types contributing to road accidents. However, this study did not find evidence of trucks' contribution to accident severity. The time of day has a significant bearing on the accident count. Specifically, the night accidents variable was the largest explanator in the accident count model. This confirms the theory that more accidents are likely to occur at night (John \& Shaiba 2019) because of decreased visibility and in some instances weakened policing. However, the variable was insignificant in the fatalities model, inconsistent with findings by Wang et al. (2019) and Ashraf et al. (2019). In Botswana, this resonates with the reality of roaming animals, which are notorious for causing many accidents, especially at night. The mere expansion of road infrastructure can be instrumental in reducing road crashes. In the accident count model, the road infrastructure variable displayed an inverse relationship, consistent with the findings of Štefko et al. (2014).

\section{Conclusion and recommendations}

The objective of this study was to determine the causes of road traffic accidents and fatalities in Botswana. Overall, statistics on accidents and fatalities have been contained in the last decade, with little variation from year to year. However, fatalities remain high proportional to country population, a common occurrence in developing economies. Considering the results of the computed OLS models, the 
accident count model is more robust than the fatalities model. The models also presented unexpected outcomes, especially on the direction of the relationship between the explanatory and dependent variables. The most significant observation here is that the two phenomena (accident count and fatalities) behave differently. The accident count model has seven explanatory variables against the four of the fatalities model. Fuel imports (value) and cars were the only two variables common in both models. In both models, no other variable matched the night accidents in explanatory power. This implies that driving at night increases the chances of accidents more than any other factor. There is no doubt from the results that an increase in the stock of cars in the country has resulted in an increase in road activity, leading to an increased road accident count, as evidenced by the positive coefficient of fuel imports (volume).

The study's findings and interpretation of results provided sufficient evidence to suggest that exposure remains a critical explanator of both accident count and severity - that as travel distance increases, the risk of road crashes and fatalities occurring cumulatively increases. Further, an increase in the number of passenger cars increases the occurrence of accidents. On the other hand, expansion of road infrastructure is likely to lead to a decrease in the number of accidents, particularly if the rate of expansion is not overtaken by the increase in vehicle population. In the Botswanan context, accidents are more likely to occur at night than during the day. However, the model does not support the assertion that fatalities are more likely to occur during the night-time.

Improvements in the collection of road traffic data, both in accuracy and in terms of capturing variables that are not currently measured, like vehicle kilometres, which are key in the determination of exposure, are vital. Poor data in one or more variables may distort the aggregate models, misinforming interventions in the process. For this purpose, Rolison et al. (2018) propose continuous updating of accident forms to capture data on all road accident causes. From a policy perspective, regulations on the management of car population and road activity should be considered. Specifically, importation of used vehicles should be heavily taxed. Investment in both passenger and freight rail transport by developing countries like Botswana would ease the burden of congestion on the roads (Saruchera 2017), thereby decreasing exposure and consequently reducing accidents. Whilst there is a need to understand fully the causes of night accidents, at first approximation, there is need for improved policing.

\section{Limitations and future research}

Where data are involved, there are bound to be limitations. There were challenges in collating data from different sources. However, there were attempts by the researcher to corroborate data from different sources. Proxy variables were used where data was not available on natural variables, which may challenge the accuracy of the models. Ideally, the preference is to measure any phenomenon as it occurs in its purest form.
However, the results demonstrate that the improvisation of using the volume of fuel imports proved worthwhile. Because of limitations of data, these results are rather indicative and must be interpreted with caution. Future research should investigate the causes of pedestrian fatalities, considering they account for a significant portion of the total fatalities. Considering that night accidents have the highest positive coefficient in the accident count model, there is a need to investigate extensively the causes of night accidents specifically.

\section{Acknowledgements}

The author acknowledges Christopher J. Savage for being a reliable mentor and sounding board for his ideas in putting this article together. The author is forever indebted to his wife, Onalenna Segaetsho Mphela, who always reads and edits his work and provides the moral support he needs.

\section{Competing interests}

The author declares that no competing interests exist.

\section{Author's contributions}

I declare that I am the sole author of this research article.

\section{Funding information}

This research received no specific grant from any funding agency in the public, commercial or not-for-profit sectors.

\section{Data availability statement}

Data sharing is not applicable to this article as no new data were created or analysed in this study.

\section{Disclaimer}

The views and opinions expressed in this article are those of the author and do not necessarily reflect the official policy or position of any affiliated agency of the author.

\section{References}

Ashraf, I., Hur, S., Shafiq, M. \& Park, Y., 2019, 'Catastrophic factors involved in road accidents: Underlying causes and descriptive analysis', PLOS One 14(10), e0223473. https://doi.org/10.1371/journal.pone.0223473

Basagana, X., Escalera-Antezana, J.P., Dadvand, P., Llatje, O., Barrera-Gomez, J., Cunillera, J. et al., 2015, 'High ambient temperatures and risk of motor vehicle crashes in Catalonia, Spain (2000-2011): A time-series analysis', Environmental crashes in Catalonia, Spain (2000-2011): A time-series analysis', Environmental
Health Perspectives 123(12), 1309-1316. https://doi.org/10.1289/ehp.1409223

Benner, L. Jr., 1979, 'Crash theories and the implications for research', American Association of Automotive Medicine Quarterly Journal 1(1), viewed 03 May 2020 from http://www.ludwigbenner.org/papers/AAAM.html.

Cioca, L. \& Ivascu, L., 2017, 'Risk indicators and road accident analysis for the period 2012-2016', Sustainability 9(9), 1530. https://doi.org/10.3390/su9091530

Conto, A. \& Ferreira, S., 2011, 'A note on modeling road accident frequency: A flexible elasticity model', Accident Analysis \& Prevention 43(6), 2104-2111. https://doi. org/10.1016/j.aap.2011.05.033

Cottrell, A. \& Lucchetti, R.A., 2018, Gret/ 2018c, computer software, viewed 29 March 2020, from $\mathrm{http}: / /$ gretl.sourceforge.net.

Cristian, D. \& Lucian, T., 2019, 'Considerations on the role of modernizing the road infrastructure in the prevention of road accidents', MATEC Web of Conferences 290(1), 06004. https://doi.org/10.1051/matecconf/201929006004

Ding, Y., Zhou, J., Yang, J. \& Laflamme, L., 2017, 'Demographic and regional characteristics of road traffic injury deaths in Jiangsu Province, China', Journal of Public Health 39(3), e79-e87. https://doi.org/10.1093/pubmed/fdw058 
Fridstrøm, L. 1999, 'An econometric model of car ownership, road use, accidents, and their severity (Essay 3)', in Econometric models of road use, accidents, and road investment decisions, Volume II, Institute of Transport and Economics, pp. 1-292 Oslo, Norway, viewed 19 March 2019, from https://www.toi.no/getfile. Oslo, Norway, viewe
php?mmfileid $=6030$.

Government of Botswana, 2008, Road Traffic Act 27 of 2008, Government of Botswana, Gaborone.

Government of Botswana, 2014, International merchandise trade statistics annual report - 2011, Statistics Botswana, viewed 25 February 2020, from http://www. statsbots.org.bw/sites/default/files/publications/Botswana $\% 20 \% 20$ International\%20Trade $\% 20$ Statistics $\% 20 \% 20$ Annual $\% 20$ Report $\% 202011$.pdf.

Government of Botswana, 2015, International merchandise trade statistics annual report - 2015, Statistics Botswana, viewed 25 February 2020, from http://www. statsbots.org.bw/sites/default/files/publications/IMTS\%20ANNUAL\%20 REPORT\%202015.pdf.

Government of Botswana, 2016, International merchandise trade statistics annual report - 2012, Statistics Botswana, viewed 25 February 2020, from http://www. statsbots.org.bw/sites/default/files/publications/IMTS\%20Annual\%20 Report\%202012.pdf

Government of Botswana, 2018a, Transport and infrastructure statistics report 2017, Statistics Botswana, viewed 02 May 2020, from http://www.statsbots.org. bw/sites/default/files/publications/2017\%20Transport $\% 20 \% 20$ Infrastructure $\% 20$ Statistics $\% 20$ Report.pdf.

Government of Botswana, 2018b, International merchandise trade statistics monthly digest - December 2017, Statistics Botswana, viewed 25 February 2020, from http://www.statsbots.org.bw/sites/default/files/publications/IMTS $\% 20$ DECEMBER\%202017.pdf.

Government of Botswana, 2019a, International merchandise trade statistics annual report - 2013/2014, Statistics Botswana, viewed 25 February 2020, from http:// www.statsbots.org.bw/sites/default/files/International\%
Trade\%20Statistics\%20Annual\%20Report\%202013-14.pdf.

Government of Botswana, 2019b, International merchandise trade statistics annual report - 2016, Statistics Botswana, viewed 25 February 2020, from http://www. statsbots.org.bw/sites/default/files/publications/IMTS\%20Annual\%20 statsbots.org.bw/sit
Report\%202016_0.pdf.

Hakkert, A.S. \& Braimaister, L., 2002, The uses of exposure and risk in road safety studies, viewed 03 May 2020, from https://www.swov.nl/sites/default/files/ publicaties/rapport/r-2002-12.pdf.

John, M. \& Shaiba, H., 2019, 'Apriori-based algorithm for Dubai road acciden analysis', Procedia Computer Science 163(1), 218-227. https://doi.org/10.1016/ j.procs.2019.12.103

Levulytė, L., Baranyai, D., Sokolovskij, E. \& Török, Á., 2017, 'Pedestrians' role in road accidents', International Journal for Traffic \& Transport Engineering 7(3), 328-341.

Lloyd, L.K. \& Forster, J.J., 2014, 'Modelling trends in road accident frequency Bayesian inference for rates with uncertain exposure', Computational Statistics and Data Analysis 73(1), 189-204. https://doi.org/10.1016/j.csda.2013.10.020

Luke, R. \& Heyns, G.J., 2014, 'Reducing risky driver behaviour through the implementation of a driver risk management system', Journal of Transport and Supply Chain Management 8(1), Art. \#146. https://doi.org/10.4102/jtscm.v8i1.146

Moyer, J.D., Eshbaugh, M. \& Rettig, J., 2017, 'Cost analysis of global road traffic death prevention: Forecasts to 2050', Development Policy Review 35(6), 745-757. https://doi.org/10.1111/dpr.12263

Mphela, T., 2011, 'The impact of traffic law enforcement on road accident fatalities in Botswana', Journal of Transport and Supply Chain Management 5(1), 264-277. https://doi.org/10.4102/jtscm.v5i1.77

Mupimpila, C., 2008, 'Aspects of road safety in Botswana', Development Southern Africa 25(4), 425-435. https://doi.org/10.1080/03768350802318506
Naqvi, N.K., Quddus, M.A. \& Enoch, M.P., 2020, 'Do higher fuel prices help reduce road traffic accidents?', Accident Analysis \& Prevention 35(1), 105353. https://doi. road traffic accidents?

Parvareh, M., Karimi, A., Rezaei, S., Woldemichael, A., Nili, S., Nouri, B. et al., 2018, 'Assessment and prediction of road accident injuries trend using time-series models in Kurdistan', Burns \& Trauma 6(1), 9. https://doi.org/10.1186/s41038018-0111-6

Pego, M., 2009, 'Analysis of traffic accidents in Gaborone, Botswana', Master of Arts Dissertation, University of Stellenbosch.

Perrels, A., Votsis, A., Nurmi, V. \& Pilli-Sihvola, K., 2015, 'Weather conditions, weathe information and car crashes', ISPRS International Journal of Geo-Information 4(1) 2681-2703. https://doi.org/10.3390/ijgi4042681

Pulido, J., Barrio, G., Hoyos, J., Jiménez-Mejías, E., Martín-Rodríguez, M.M., Houwing S. et al., 2016, 'The role of exposure on differences in driver death rates by gender and age: Results of a quasi-induced method on crash data in Spain', Accident Analysis \& Prevention 94(1), 162-167. https://doi.org/10.1016/j.aap.2016.05.020

Rahimi, E., Shamshiripour, A., Samimi, A. \& Mohammadian, A.K., 2020, 'Investigating the injury severity of single-vehicle truck crashes in a developing country' Accident Analysis \& Prevention 137(1), 105444. https://doi.org/10.1016/ j.aap.2020.105444

Rolison, J.J., Regev, S., Moutari, S. \& Feeney, A., 2018, 'What are the factors that contribute to road accidents? An assessment of law enforcement views, ordinary drivers' opinions, and road accident records', Accident Analysis \& Prevention 115(1), 11-24. https://doi.org/10.1016/j.aap.2018.02.025

Romilly, P., 1999, 'Substitution of bus for car travel in urban Britain: An economic evaluation of bus and car exhaust emission and other costs', Transportation Research Part D: Transport and Environment 4(2), 109-125. https://doi. org/10.1016/S1361-9209(98)00028-5

SACU Secretariat, 2013, Merchandise trade statistics, Southern African Customs Union, Namibia, viewed 10 December 2018, from http://www.sacu.int/docs/ reports/2014/SACU-Merchandise-Trade-Statistics-2013.pdf.

Saruchera, F., 2017, 'Rail freight transportation concerns of developing economies: A Namibian perspective', Journal of Transport and Supply Chain Management 11(1), a288. https://doi.org/10.4102/jtscm.v11i0.288

Shen, S., Benedetti, M.H., Zhao, S., Wei, L. \& Zhu, M., 2020, 'Comparing distance and time as driving exposure measures to evaluate fatal crash risk ratios', Accident Analysis \& Prevention 142(1), 105576. https://doi.org/10.1016/j. aap.2020.105576

Štefko, R., Kubák, M. \& Bačík, R., 2014, 'Determinants of the road traffic accident rate in Slovak Republic', Applied Mechanics \& Materials 708(1), 130, viewed 23 April 2020, from http://search.ebscohost.com/login.aspx?direct=true\&db=edb\&AN= $100088242 \&$ site $=$ eds-

Torrao, G., Coelho, M. \& Rouphail, N., 2012, 'Effect of vehicle characteristics on crash severity: Portuguese experience', Injury Prevention 18. https://doi.org/10.1136/ injuryprev-2012-040590u.41

Wang, D., Liu, Q., Ma, L., Zhang, Y. \& Cong, H., 2019, 'Road traffic accident severity analysis: A census-based study in China', Journal of Safety Research 70(1), 135-147. http://doi.org/10.1136/injuryprev-2012-040590u.41

World Bank, 2017, The high toll of traffic injuries: Unacceptable and preventable, viewed 02 May 2020, from https://openknowledge.worldbank.org/bitstream/ handle/10986/29129/HighTollofTrafficlnjuries. pdf? sequence=5\&isAllowed=y.

World Health Organization, 2004, World report on road traffic injury prevention, WHO, Geneva.

World Health Organization, 2015, Global status report on road safety 2015, viewed 27 May 2020, from http://www.who.int/violence_injury_prevention/road safety_status/2015/en/. 